\title{
Primary care in the Asia-Pacific region: challenges and solutions
}

Richard Hays ${ }^{1}$, Lam Tai Pong ${ }^{2}$ and Zorayda Leopando ${ }^{3^{*}}$

Asia Pacific Family Medicine aims to provide a forum for the dissemination of high quality regional research and to enhance the standards of family medicine by focusing on best practice. The ultimate goal is to enhance the provision of primary care to our patients.

\section{Regional diversity}

Geographically large and home to a substantial proportion of the world's population, the region includes substantial diversity in culture, language, economic maturation and demography. Most nations share problems such as ageing populations, increasing complexity of disease, workforce shortages, a need for increasing technology and accelerating costs. Some project substantial growth in middle class affluence and aspiration, which are major drivers of demand for improved quality. Some still struggle with high child mortality and infectious disease prevalence, particularly with Malaria and Dengue fever. While some show potential to be the economic powerhouses of the near future, a few have substantial poverty, sometimes related to civil warfare and terrorism. Yet these health issues are managed by diverse health care systems, with different proportions of primary, secondary and tertiary care, access to health care and funding models. The Asia-Pacific region shares with the rest of the world the challenges of allocating health care resources to achieve efficiently an increase in the quality of health care. In a sense the region has the potential to be a fascinating laboratory for comparing just how the shared challenges can be managed.

\section{Healthcare system diversity}

There are at least three kinds of health care system within the region: the British legacy of strong, first contact, medical primary care; US-style 'competition' between primary and secondary care; and non-medical

\footnotetext{
* Correspondence: zeleopando@mail.upm.edu.ph

${ }^{3}$ Department of Family and Community Medicine, University of the Philippines Manila, Manila, Philippines

Full list of author information is available at the end of the article
}

primary health care, all either with or without universal access. Family Medicine is not always recognized as a defined specialty and, where present, requires variable levels of training and recognition. Health care is often delivered by innovative categories of less trained and less expensive workers. Primary medical care is believed to be associated with more equitable and more costefficient health care, and private primary care has been shown to be 'better' in Hong Kong when delivered through private rather than public practices [1]. On the other hand, non-medical primary care works well in less developed nations, achieving high vaccination rates and success with other prevention measures. China has a mixed system, but has some of the best health statistics in the world as well as now challenging the USA, UK and Europe for leadership in the advance of medical science, begging the question: how?

\section{Healthcare system reforms}

Major reforms to health systems are under consideration almost everywhere, as costs escalate much faster than growth in national wealth. For example, the USA, home to a bimodal system of both excellent (technical quality of) and poor (access to) health care, wants to extend access. The UK has a universal access system that is struggling to cope due to rapid cost increases. Within the region, Singapore plans to increase access and, in parallel with Malaysia, is seeking to become a health hub for the rest of Asia, perhaps benefiting from medical tourism. Hong Kong is considering increasing the size of the private health system [2]. Australia and New Zealand have universal access systems, but access often requires some co-payment through a form of governmentsupported public health system.

\section{Family medicine training}

Many countries in the region have formal postgraduate training in Family Medicine but their duration, content and pathways vary [3]. It is not a question of one better than the others. They are established with specific 
regulations and specifications in mind [4-7]. This also leads to varying levels of recognition by other medical specialties, with specialist status in some countries [8-10]. Furthermore, mandatory referrals from primary care practitioners are not required in some systems within the region. How do these variations affect the interface between primary care and secondary care?

Common mental health disorders e.g. anxiety and depression offers a good example to examine the roles that primary care can play in the region. These high prevalent disorders cannot be dealt with by specialist psychiatrists alone. However, are most primary care professionals competent in dealing with them? What kind of training would help to enhance their skills to a level sufficient for optimal care? Other high prevalent disorders e.g. hypertension and diabetes mellitus offer similar opportunities to examine the role of primary care in different localities.

\section{Opportunities}

The natural experiment we are observing in the AsiaPacific region suggest several research questions. Which of the three health system models is appropriate for which conditions? Is there a relationship between presence of a recognized Family Medicine specialty and health care quality?

As primary care gets better developed in the region, we must also recognize the different needs of different populations. In countries with established primary care, most of the general population recognize their general practitioners/family physicians as their first contact point with the healthcare system. However, such is not the situation in countries where primary care is relatively unestablished but is being promoted [11-15]. It would also be highly relevant to examine how acceptable Family Medicine is in being the first contact care for the general population: is this about improving access or 'gate-keeping'?

There is never going to be one model fits all. However, there are certainly lessons and experiences to be shared among the different systems. Asia Pacific Family Medicine welcomes submissions from different systems so that advances are made to enhance our service to our patients.

\section{Competing interests}

The authors declare that they have no competing interests.

\section{Authors' contributions}

The first draft was written by RH. LTP and ZEL reviewed, comments and added a few statements. All authors read and approved the final manuscripts.

\section{Editors' note}

This is the "Valedictory Remark" by Professor Richard Hays as the outgoing Co Editor-in-Chief of Asia Pacific Family Medicine. The Co Editors-in-Chief and the Editorial Board would like to thank Professor Hays for his contributions to the journal since its inception. We would also like to welcome our new Co Editor-in-Chief, Professor Kelsey Hegarty.

\section{Author details}

${ }^{1}$ Bond University, Gold Coast, Queensland, Australia. ${ }^{2}$ Department of Family Medicine and Primary Care, The University of Hong Kong, Hongkong, Hong Kong. ${ }^{3}$ Department of Family and Community Medicine, University of the Philippines Manila, Manila, Philippines.

Received: 17 June 2012 Accepted: 7 August 2012

Published: 5 October 2012

\section{References}

1. Wong SY, Kung K, Griffiths SM, Carthy T, Wong MC, Lo SV, Chung VC, Goggins WB, Starfield B: Comparison of primary care experiences among adults in general outpatient clinics and private general practice clinics in Hong Kong. BMC Public Health 2010, 10:397.

2. Hong Kong Special Administrative Region Government: Healthcare Reform Second Stage Public Consultation Document "My Health, My Choice". Food and Health Bureau. 2010. http://www.myhealthmychoice.gov.hk/en/ fullConsolDoc.html.

3. Hays RB, Morgan S: Australian and overseas models of general practice training. Med J Australia 2011, 194(11):S63-S66.

4. Osman H, Romani M, Hlais S: Family medicine in Arab countries. Fam Med 2011, 43:37-42.

5. Prueksaritanond $\mathrm{S}$, Tuchinda P: General practice residency training program in Thailand: past, present, and future. J Med Assoc Thai 2001, 84:1153-1157.

6. Sturmberg J, Heard S: General practice education in Australia. Current issues. Aust Fam Physician 2004, 33:353-355.

7. Wun YT, Lam TP, Lam KF, Li DK, Yip KC: Family medicine training in Hong Kong: similarities and differences between family and non-family doctors. Hong Kong Med J 2011, 17:47-53.

8. Guides to Vocational Training. The Hong Kong College of Family Physicians. http://www.hkcfp.org.hk/index.php? option=com_content\&view=article\&id=59\&ltemid=77\&lang=en.

9. Jones R: Accurately assessing candidates for general practice. Aust Fam Physician 2009, 38:225-227.

10. Sturmberg JP, Atkinson K, Farmer EA: Research and Development Subcommittee, Board of Examiners, The Royal Australian College of General Practitioners. Standards and performance - attainment and maintenance of professional capabilities. Aust Fam Physician 2005, 34:371-373.

11. WHO: Report 2008: Primary Health Care, Now More Than Ever. Geneva: World Health Organization; 2008.

12. Abyad A, Al-Baho AK, Unluoglu I, Tarawneh M, Al Hilfy TK: Development of family medicine in the middle East. Fam Med 2007, 39:736-741.

13. Montegut AJ, Cartwright CA, Schirmer JM, Cummings S: An international consultation: the development of family medicine in Vietnam. Fam Med 2004, 36:352-356.

14. Nieman LZ, Kvale PJ, Fu X, Gu Y, Strobel HW: Bringing a family practice model of health to the People's Republic of China. Fam Med 2001 33:696-701. Review.

15. Murai M, Kitamura K, Fetters MD: Lessons learned in developing family medicine residency training programs in Japan. BMC Med Educ 2005, 15:5-33.

doi:10.1186/1447-056X-11-8

Cite this article as: Hays et al:: Primary care in the Asia-Pacific region: challenges and solutions. Asia Pacific Family Medicine 2012 11:8. 